\title{
The Anatomy of Brand Name Translation Under Skopos Theory: A Model of Customer Satisfaction, Awareness of Translation Strategy Use and Purchase Intention
}

\author{
Che-chang Kang \\ National Changhua University of Education, Changhua, Taiwan
}

\begin{abstract}
The purpose of the study was to apply structural equation modeling (SEM) to build relations among customer satisfaction (CS), customers' awareness of translation strategy use (CA), and purchase intention (PI) on English-Chinese brand name translation. To ensure construct validity, exploratory factor analysis (EFA) was first applied in a pilot study $(N=150)$ to extract factors for each latent variable, including semantic ambiguity, faithful reflection, and smoothness under CS; grammatical competence, illocutionary competence, and sociolinguistic competence under CA; willingness to try the sample products and willingness to be updated about the products under PI. In a formal survey $(N=550)$, three self-report scales were administered on customers chosen through stratified sampling from a database. Results showed that CA exerted a direct effect on both CS and PI. In addition, CS exerted a direct effect on PI. Moreover, CA exerted an indirect effect on PI through CS as an intervening factor. More importantly, the indirect effect of CA on PI through CS was statistically more significant than the direct effect of CA on PI. This is good proof that CS assumed a critical role in the model. The model drew implications for marketing and advertising sectors on the potential value of translation strategy use and CS in brand name translation. Theoretically, the findings substantiated the referential/informative, expressive and operative functions in the realm of Skopos theory and highlighted the dual roles that translators need to play both linguistically and social-culturally when orienting strategies for brand name translation.
\end{abstract}

Keywords: brand name translation, Skopos theory, customer satisfaction (CS), translation strategy use, purchase intention $(\mathrm{PI})$

\section{Introduction}

\section{Brand Name Adaptation}

Merchandise brand name design and brand name translation are considered critical elements in advertising language, particularly in today's intercultural and globalized economy. This has contributed to a mounting academic interest in strategy use and assessment criteria for brand name translation in recent years (Alashban, Hayes, Zinkhan, \& Balazs, 2002; Dong \& Helms, 2001; Fan, 2002; Francis, Lam, \& Walls, 2002; He \& Xiao, 2003; Hong, Pecotich, \& Shultz II, 2002; Sandler \& Shani, 1992; Zhang \& Schmitt, 2001). Regarding the direct effect of brand name design in business context, Alashban et al. (2002) found that firms' cost savings and sales

Che-chang Kang, adjunct lecturer, with M.A. in translating and interpreting and pursuing a doctoral degree in TESOL, Department of English, National Changhua University of Education. 
volumes increased when brand names were more standardized. An earlier study by Sandler and Shani (1992) also revealed that companies tend to brand globally and advertise locally. Their works illuminated the importance of brand name design adaptation across different target markets within the same language system. However, they did not go any further cross-culturally by elaborating how the translators can translate the locally-advertised brand names into a different target language with a view to catering to the taste of local customers as well as maintaining its cultural appropriateness (Kang, 2014).

\section{Brand Name Translation Strategy}

As a remedial approach to the limitation to these works, scholars have proposed a wide variety of strategies for brand name translation. In a case study, Dong and Helms (2001) investigated US brands in China and stated that developing a world brand is more than just a careful literal translation, as meanings vary greatly across norms, attitudes, beliefs, and cultures. Similarly, Hong et al. (2002) found that translation of brand names was highly correlated with product-related cues, including physical quality, perceived origin, perceived quality, price and purchase intensions. Interestingly, a dichotomous categorization was specified, i.e., a phonetic translation is mandatory for less-known products, while retaining the original names is suggested for existing strong brands (Hong et al., 2002). Likewise, a comparative analysis of English and Chinese brand names of Fortune-500 companies by Francis et al. (2002) revealed that transliteration was the dominant use of strategy, while in other cases strategies such as adding features (cultural symbols, product benefits, and positive connotation) were also observed. Fan (2002) also suggested that when localizing brand names, meaning should be prioritized over its sound although it is still appropriate to maintain phonetic links to originals in other cases. Moreover, factors like product benefits, brand positioning, and cultural values ought to be emphasized in similar vein (Fan, 2002). Numerous strategies proposed in the literature reflected the diverse nature of complexity lying within the domain of brand name translation. A niche nevertheless still lies out there regarding how to evaluate the quality of brand name translation or how to adopt specific criteria which objective assessment can be based on. Also, scant analysis has been done on building relations between translation strategy use for brand name translation and evaluative response from the customers, who are the major end users of the products (Kang, 2014).

\section{Assessment and Satisfaction on Brand Name Translation}

In response, Zhang and Schmitt (2001) presented a conceptualized framework and formulated guidelines for evaluating brand name translation quality in two aspects: linguistic and cognitive analysis. The former was placed on translation methods, including phonetic (by sound), semantic (by meaning), and phono-semantic (by sound plus meaning), while the latter incorporated the variable of consumer response into consideration. Additionally, He and Xiao (2003) proposed criteria for selecting translators as well as standards for assessing the quality of brand name translation. Kang (2014) conducted a satisfaction analysis on Chinese-English brand name translation and specified different predicting factors for customers' satisfaction on brand name translation in different product types, i.e., semantic ambiguity for cosmetics and medical care products, faithful translation for food products, and smoothness for technology products. According to Kang (2014), the different satisfaction criteria adopted across different product types might have resulted from the different attributes of different product types, which further implied the different functions of translation that translators need to be aware of.

\section{Niches in Brand Name Translation Studies}

Although Kang's (2014) satisfaction analysis extended the discussion of brand name translation to 
variables like product types and customer satisfaction, no strong relations have been identified between customer satisfaction on brand name translation and customers' purchase intention. This might have invited dubious attitudes against its practical values in business contexts. The insufficient value to be drawn for business contexts in the past literature is also obvious. In one sense, review of past studies has presented an overview of the significance of brand name translation, coping translation strategies, and a systematized framework for evaluating brand name translation. On the other hand, the past studies did not provide enough concrete evidence of how the strategy use in brand name translation and customer preference on brand name exert any direct impact on customers' purchase intention, which might be a major concern for business sectors (Chang \& Wildt, 1994; Laroche, Kim, \& Zhou, 1996; Li, Daugherty, \& Biocca, 2002; Grewal, Krishnan, Baker, \& Borin, 1998).

\section{Brand Names in Business Models}

At this juncture, reference to the previous business models addressing the relationship between purchase intention and numerous customer factors is needed. In a structural equation model of price, product attribute information and purchase intention, Chang and Wildt (1994) treated purchase intention as an endogenous variable and found that product attribute information played as an important role in affecting variables such as perceived quality, perceive value and purchase intention. Some implications can be drawn from this business model. First, the variable of purchase intention was considered of paramount importance in the business context. Second, product attribute information assumed a critical role in ultimately leading to customers' purchase intention. A niche nevertheless was observed in that this study discussed the variable of product attribute information in a mono-lingual fashion. In specific terms, whether this model can be applied to cross-lingual realm is not tested.

Further building connections among purchase intention, brand familiarity, confidence in brand evaluations and brand attitudes, Laroche et al. (1996) established structural equation modeling (SEM) which showed that familiarity with a brand influences a consumer's confidence toward the brand, which in turn affects his/her intention to buy the same brand. In addition, a consumer's attitude toward a specific brand is affected by his/her familiarity with the brand. These causal relationships are tested in a multiple brand context. This study highlighted the variable of customers' perception on brand name and made a statistically firm model that connects with purchase intention. Like Chang and Wildt's model (1994), this model did not consider customer perception on brand name translation either. Championing similar emphasis on the significance of factors that entail potential causal relations with purchase intention, Grewal et al. (1998) found that brand's perceived quality exerted significant influence on perceived value. Perceived value and store image, in turn, positively influenced purchased intentions.

\section{Concluding Remarks on Literature Review}

To conclude, the review of literature on translation-related works presented a great number of theoretical translating strategies for global brand names but did not establish any convincing remark on how these theoretical discussions contain any application value in increasing customer purchase intention, which is a major issue in marketing domain. In the same token, such deficiency was observed when referring to business-related models as proposed by Chang and Wildt (1994), Laroche et al. (1996) and Grewal et al. (1998). Their models successfully highlighted the significant issue of purchase intention and built statistically solid models connecting between purchase intention and numerous customer factors such as product attribute 
information, brand familiarity, confidence in brand evaluation, brand attitudes, perceived brand quality, and perceived value. On the other side of the coin, their models might have ignored the important factor of brand name when translated.

\section{The Current Study}

Built on the above two sections of literature review on translation-related studies and business-related ones, the current study identified three factors that were important yet rarely touched upon in the past studies: (1) customer satisfaction on brand name translation (CS), (2) customers' awareness on the strategy employed during the brand name translation works (CA), and (3) customers' purchase intention after reading the translated brand names (PI). The first two factors were identified because customers' attitudes have been regarded as important reference in business models but have not been extended to translation domain (Chang \& Wildt, 1994; Laroche et al., 1996; Li et al., 2002; Grewal et al., 1998). The third factor was identified because it served to broaden the current studies on brand name translation to potential business application realm.

\section{Research Hypotheses}

The selection of these three factors as niches in the domain of brand name translation was at best the result of theoretical speculation through the review of literature. Specifically, the hypothetical relations among these factors were not tested yet. Empirical evidence is needed to further clarify these relations. Understanding these relations is important in shedding light on the potential value of customers' attitudes toward brand name translation and the use of strategy use and most importantly their relations with customers' purchase intention. To provide such evidence, an SEM was applied to investigate four hypotheses that specify three unidirectional paths (see Figure 1 for the graphic representation):

(1) CA has a direct and positive effect on CS.

(2) CS has a direct and positive effect on PI.

(3) CA exerts an indirect effect on PI through CS as an intervening factor.

(4) The indirect effect of CA on PI is smaller than the direct effect of CA on PI.

\section{Definition of Terms}

The following terms were widely used in the study. To avoid semantic ambiguity, they received the following operational definitions.

Customer satisfaction. A review of the existing literature reveals a wide range of variance on the definitions of consumer/customer satisfaction (Giese \& Cote, 2000). Such definitional incoherence and lack of consensus might cause semantic confusion when the term is used in the current study. Therefore, the researcher decided to refer to the definitional framework of consumer satisfaction proposed by Giese and Cote (2000), who outlined three important components of consumer satisfaction. First, consumer satisfaction is a response (emotional or cognitive). Second, the response pertains to a particular focus (expectations, product, consumption experience, etc.). Third, the response occurs at a particular time (after consumption, after choice, based on accumulated experience, etc.). A summarized version of the framework contains three aspects: affective response, focus, and timing. It should be noted that Giese and Cote's (2000) framework used the term "consumer" rather than "customer", which is used in the current study. The researcher decided to adopt the wording of "customer" because the subjects surveyed in the study were not on-the-spot purchasers (people who consume products) of brand name translation - an abstract, intangible component of the products. Instead, the subjects surveyed were old consumers chosen through stratified sampling from a digital customer database of a 
shopping mall. They might be potential purchasers of the products but are not at any rate on-the-spot purchaser of "brand name translation", which can be evaluated but not bought. Even though on-line Oxford dictionary ${ }^{1}$ treated the two words as synonyms, for the sake of semantic clarity and uniformity, the current study decided to adopt the term "customer" instead of "consumer". However, such linguistic alteration does not cause any bias on the definitional orientation of "satisfaction" in Giese and Cote's (2000) conceptual framework. Under this framework, the current study operationalized the term "customer satisfaction" as customers' liking (affective response) toward the Chinese translation of English brand names (focus) when attending the survey (timing).

Translation strategy. To give a definition of translation strategy that would be applicable to all possible communicative situations it is necessary to take into account an obvious fact that translation is an activity performed in a certain environment. Therefore, the current study followed Sdobnikov (2011) in defining the term translation strategy. In this study, translation strategy is defined as a general program of the translator's activity worked out on the basis of the general approach to translation in a specific communicative situation, determined by the particular parameters of the situation and the translation goal and, in its turn, determining the character of the translator's professional behavior (Sdobnikov, 2011).

Purchase intention. Academically, purchase intention is the implied promise to buy the product again whenever one makes next trip to the market (Fandos \& Flavián, 2006; Halim \& Hamed, 2005). In addition, BusinessDictionary.com ${ }^{2}$ gave a more general definition of "a plan to purchase a particular good or service in the future". Both these definitions conform to how this term is treated in the current study. Specifically, in the survey, the researcher seeks to explore subjects' potential purchase intention of the products after reading or understanding the Chinese translation of English brand names.

Since these terms are constructs that are not easily measured through one clear-cut question items, a list of question items will be designed and exploratory factor analysis (EFA) will be applied to investigate the construct validity of these latent variables.

\section{Methodology}

\section{Overview}

SEM technique was applied to build causal relations among three constructs: customer satisfaction on brand name translation (CS), customers' awareness of translation strategy use (CA), and purchase intention (PI). One scale was adopted from Kang (2014) and two self-designed scales were examined through EFA in a pilot study $(N=105)$ to confirm the construct validity. In addition, Cronbach's $\alpha$ was computed to verify the internal consistency of the question items. In the formal survey $(N=550)$, the researcher followed the advice of Anderson and Gerbing (1988) and Williams and Hazer (1986), who suggested two steps to be taken before proceeding to SEM: using (1) Cronbach's $\alpha$ and (2) confirmatory factor analysis (CFA) to certify the construct reliability, convergent validity, and discriminant validity. By applying the SEM, the researcher intended to examine whether the proposed theoretical model fit the sampled data based on a variety of statistical indices: chi-square $\left(\chi^{2}\right)$, normed chi-square $\left(\chi^{2} / d f\right)$, absolute fit measures (GFI, AGFI, RMR, and RMSEA), incremental fit measures (NNFI, IFI, and CFI), and parisomy fit measures (PGFI). Following the model fitness check, the values of $\lambda$ and $\beta$ (standardized regression weights or standardized parameter estimates) for the structural model were computed. Finally, the default model was modified based on modification indices and the past literature

\footnotetext{
${ }^{1} \mathrm{http}: / /$ www.oxforddictionaries.com/definition/english/customer?q=customer

${ }^{2} \mathrm{http} / / / \mathrm{www} \cdot$ businessdictionary.com/definition/purchase-intention.html
} 
(when needed) and the causal relations among constructs were specified.

\section{Instruments}

Instruments include a customer satisfaction on brand name translation scale (CS scale), a customers' awareness of translation strategy use scale (CA scale) and purchase intention scale (PI scale). The CS scale was adopted from Kang (2014), who studied customer satisfaction on brand name translation across different product types. Since Kang (2014) developed the scale through EFA, the scale was considered to have good reliability and construct validity. According to Kang (2014), the scale contained 12 items. The factor analysis established a three-factor structure, respectively named Semantic Ambiguity (items 1, 3, 7, and 11), Smoothness (items 4, 6, 9, and 10), and Faithful Reflection of the Product Information (items 2, 5, 8, and 12) (see the Appendix: Survey on Brand Name Translation for the CS scale).

The CA scale included six 5-point Likert-type questions, ranging from 1 ("strong disagreement") to 5 ("strong agreement"). The scale was theoretically based on the components of translational language competence (Cao, 1996): grammatical competence, textual competence, illocutionary competence, and sociolinguistic competence. The former two components were categorized under organizational competence while the latter two were under pragmatic competence. The current study excluded textual competence and only focused on the grammatical, illocutionary, and sociolinguistic competence considering the fact that brand name translation is a small-unit translation without a textual context. Two items were respectively written to measure customers' awareness of each of the three translator competence in the brand name translation (see the Appendix: Survey on Brand Name Translation for the CA scale).

The PI scale included four 5-point Likert-type questions, ranging from 1 ("strong disagreement") to 5 ("strong agreement"). The scale was intended to measure customers' purchase intention after reading the brand name in English/brand name translation in Chinese. Since purchase intention is an abstract construct, four items were written as observed variables based on the definition of purchase intention by various scholars (Fandos \& Flavián, 2006; Halim \& Hamed, 2005). Two items were intended to measure "customers' willingness to try the sample products". The other two items were intended to measure "customers' willingness to be updated about the products" (see the Appendix: Survey on Brand Name Translation for the PI scale).

Both the CA and PI scales were self-designed and their reliability and construct validity were unconfirmed. Therefore, EFA was conducted on the two scales in a pilot study $(N=105)$. The principal component factoring with a minimum-eigenvalue of 1.0 and varimax rotation were used. The results of Bartlett text of sphericity (Bartlett's Test) and KMO were illustrated in Table 1.

Table 1

KMO and Bartlett's Test of Sphericity

\begin{tabular}{lll}
\hline Scale & KMO & Bartlett's Test \\
\hline CA & 0.81 & $1121^{* * *}$ \\
PI & 0.82 & $1209^{* * *}$ \\
\hline
\end{tabular}

Note. ${ }^{* * *} p=.000$.

Table 1 shows that both scales have acceptable KMO (> .08) and significant Bartlett's Test values, indicating that in both scales the observed variables (raw data in each question item) are highly correlated with one another. Therefore, they are suitable for using the EFA to extract common factors. Table 2 shows the EFA of CA scale. 
Table 2

Exploratory Factor Analysis of CA

\begin{tabular}{llllll}
\hline Factor & Items & Factor loadings & Eigenvalue & Explanatory variance (\%) & Cronbach's $\alpha$ \\
\hline Grammatical & 1 & 0.688 & 3.646 & 32.785 & 0.88 \\
competence & 3 & 0.763 & & & 0.89 \\
Illocutionary & 2 & 0.823 & 3.270 & 30.436 & \\
competence & 4 & 0.851 & & & 0.86 \\
Sociolinguistic & 5 & 0.719 & 1.461 & 9.133 & \\
competence & 6 & 0.835 & &
\end{tabular}

Accumulated explanatory variance: $78.633 \%$

Total reliability: 0.86

According to Table 2, the factor analysis extracts three factors from the scale. This result corresponds to the theoretical foundation of the scale. Each item has high factor loadings $(>.06)$ and all the Cronbach's $\alpha$ coefficients are over .08 . The accumulated explanatory variance is $78.6 \%$. These results indicated that all the question items (observed variables) are highly correlated with the extracted factors (latent variables) and generally produce consistent answers. In addition, the three factors have great contributions in explaining the total variance of the data in the scale. Therefore, the researcher confirmed acceptable internal consistency of the items and construct validity of the scale. The three factors are respectively labeled Grammatical Competence (items 1 and 3), Illocutionary Competence (items 2 and 4), and Sociolinguistic Competence (items 5 and 6) (see Appendix for the PI scale). Table 3 shows the EFA of PI scale.

Table 3

Exploratory Factor Analysis of PI

\begin{tabular}{llllll}
\hline Factor & Items & Factor loadings & Eigenvalue & $\begin{array}{l}\text { Explanatory } \\
\text { variance (\%) }\end{array}$ & Cronbach's $\alpha$ \\
\hline Willingness to try sample products & 1 & 0.788 & 4.646 & 42.785 & 0.88 \\
Willingness to be updated about & 4 & 0.863 & & & 0.89 \\
products & 2 & 0.843 & 2.270 & 26.436 & 0.89 \\
\hline
\end{tabular}

Accumulated explanatory variance: $69.221 \%$

Total reliability: 0.88

According to Table 3, the factor analysis extracts two factors from the scale. This result corresponds to the hypothetical number of factors in the scale. In addition, each item has high factor loadings $(>.07)$ and all the Cronbach's $\alpha$ cohefficients are over .08. The accumulated explanatory variance is close to $70 \%$. These results confirmed acceptable internal consistency of the items and construct validity of the scale. The two factors are labeled Willingness to Try Sample Products (items 1 and 4) and Willingness to Be Updated about Products (items 2 and 3).

Regarding SEM application, Anderson and Gerbing (1988) suggested applying the EFA (in a case study) first to specify the factor structure of the scales and then applying the CFA (in another pool of subjects) to guarantee better construct validity (e.g., convergent validity and discriminant validity) of the measurement model. Following this suggestion, the researcher decided to apply the CFA by using SPSS 22 AMOS to confirm the construct validity of the measuring model. Figure 1 represents the hypothetical measurement and structural model. 


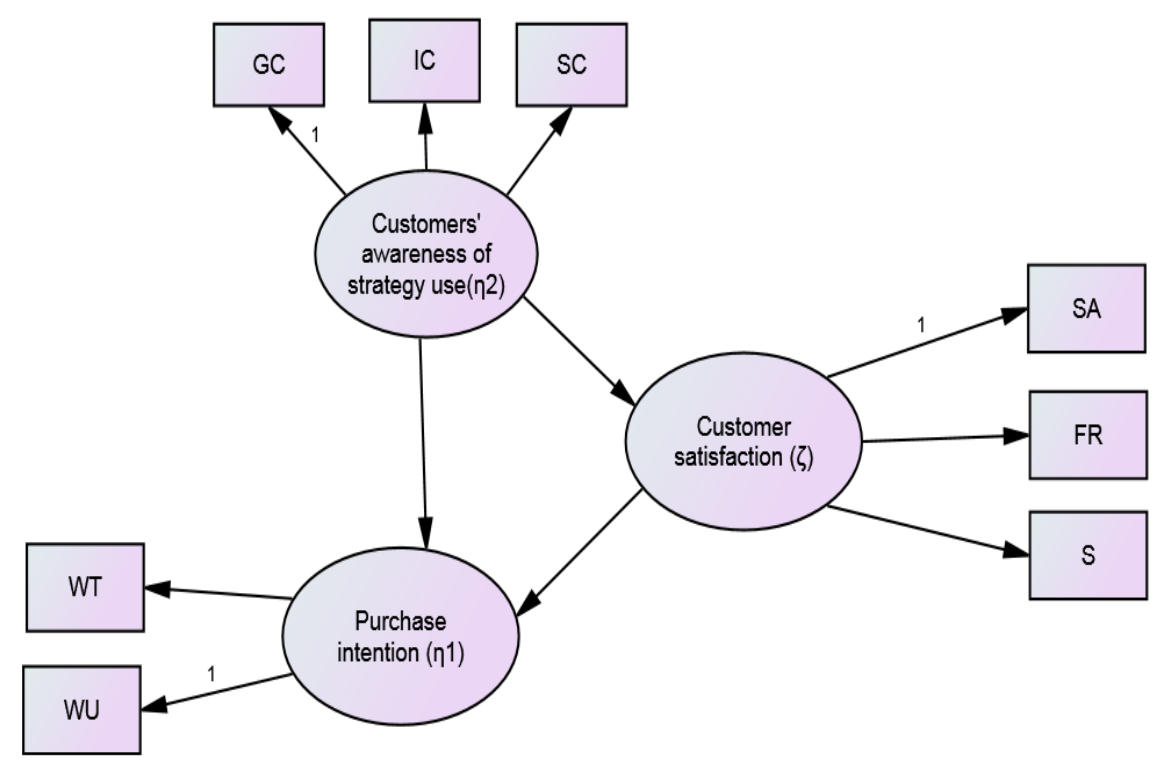

Figure 1. The hypothetical measurement and structural model.

Figure 1 is a graphic representation of the measurement and structural model, in which several abbreviations are used, as explained as follows:

(1) CS scale (SA: semantic ambiguity; FR: faithful reflection of the product information; S: smoothness)

(2) CA scale (GC: grammatical competence; IC: illocutionary competence; SC: sociolinguistic competence)

(3) PI scale (WT: willingness to try sample products; WU: willingness to be updated about products)

The CS scale (a scale for measuring the construct of customer satisfaction) is composed of three observed variables (SA, FR, and $\mathrm{S}$ ). It should be noted that in the EFA procedure, each of these variables respectively contain three question items. In the EFA result, SA, FR, and S were treated as latent variables. However, to simplify the structure of the structural equation model, Anderson and Gerbing (1988) and Williams and Hazer (1986) suggested reducing the number of indicator variables before proceeding to SEM. By following this tip, the researcher calculated the average of items 1, 3, 7, and 11 for SA; the average of items 2, 5, 8, and 12 for FR; the average of items 4, 6, 9, and 10 for S. Similar reduction procedure applies to the SA and PI scales. Now, the researcher proceeds to the CFA of the three measurement models, as illustrated in Tables 4 and 5. The researcher checked the following five sections in the CFA of the measurement models: (1) assessment of normality, (2) offending estimates, (3) fitness of the models, (4) convergent validity, and (5) discriminant validity.

Since AMOS applies maximum likelihood solution when computing CFA, a normality test needs to be done to ascertain the univariate and multivariate normality of the raw data (Mardia, 1985; Bollen, 1989; Jöreskog \& Sorbom, 1989). Table 4 illustrates that the skewness and kurtosis for each question item fall between -2 and 2, which indicate a good sign of univariate normality (Bollen \& Long, 1993). For the multivariate normality, Bollen (1989) proposed using $p(p+2)(p=$ the number of question items for each construct) as a criterion when check Mardia's coefficients of multivariate skewness and kurtosis (Mardia, 1985). As shown in Table 4, the Mardia for each scale is smaller than its corresponding $p(p+2)$, indicating that the multivariate normality is ascertained (Bollen, 1989). 
For the offending estimates check, the SFLs for each question item fall between 0.67 and $0.86(<0.95)$. In addition, all the EVs are positive and SEs fall between 0.20 and 0.58 . These results indicate that there is no sign of offending estimates in the modeling process.

Table 4

Confirmatory Factor Analysis on Measurement Models

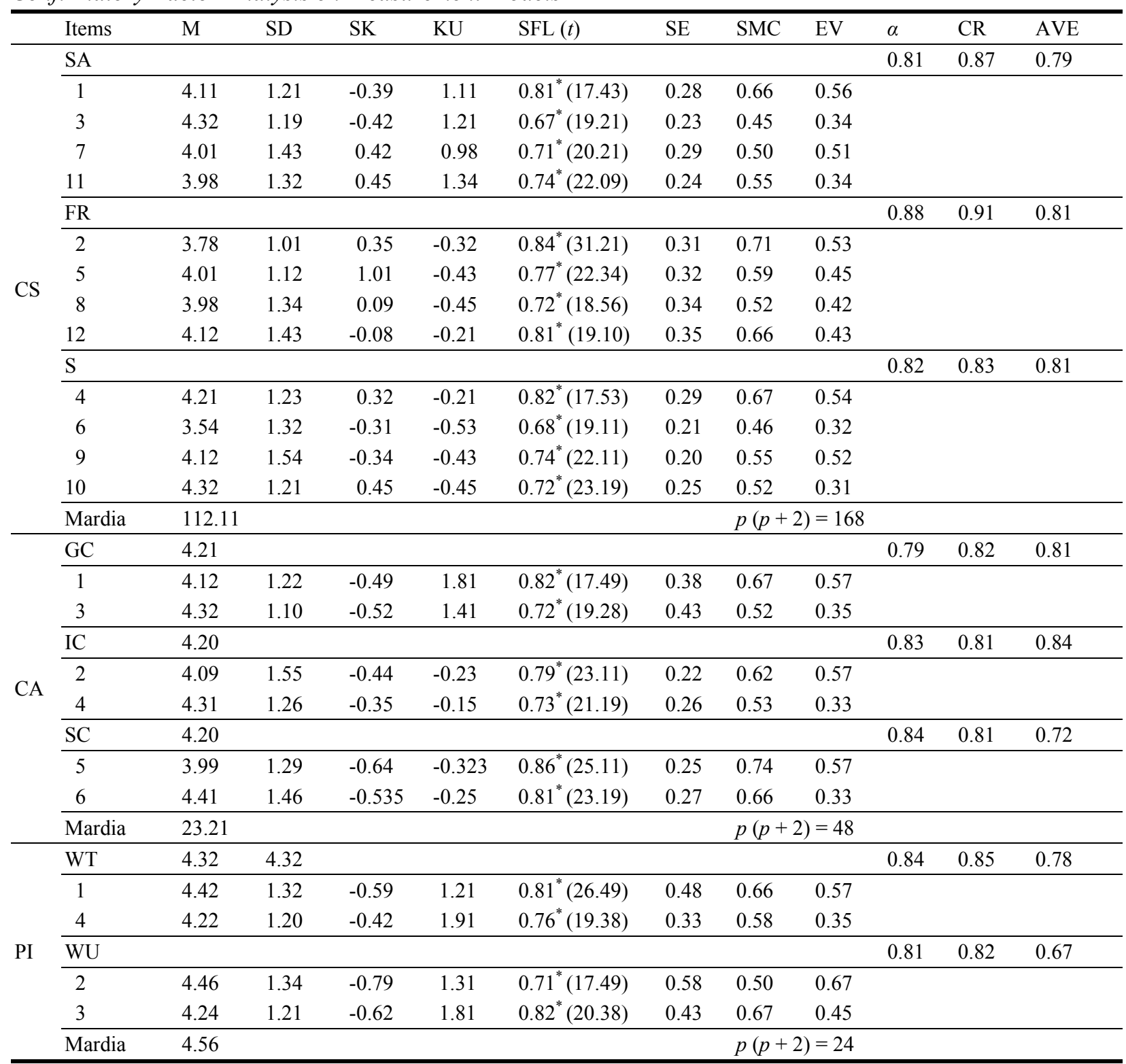

Note. M: mean; SD: standard deviation; SK: skewness; KU: kurtosis; SFL $(t)$ : standardized factor loadings $(t$ value); SE: standard error of factor loadings; SMC: squared multiple correlations; EV: error variance; $\alpha$ : Cronbach's $\alpha$; CR: composite reliability; AVE: average variance extracted; $p$ : number of observed variables.

$* p<0.05$.

Regarding the fitness of the models, Table 5 summarized a number of well-acknowledged indices, respectively categorized under absolute fitness measures, incremental fitness measures, and parisomy fitness measures (Hair, Anderson, Tatham, \& Black, 1998). In addition, $\chi^{2}$ (chi-square) and $\chi^{2} / d f$ (normed chi-square) 
were used (Bagozzi \& Yi, 1988). The chi-square of each scale was very big (> 500) and the $p$ values were smaller than the $\alpha=.05$ significant level, indicating a bad fit. However, Bagozzi and Yi (1988) cautioned that chi-square is very sensitive to sample size. In the current study, the number of subjects is 550, which is much bigger than the minimum sample size requirement suggested for SEM (Boomsma, 1982). Therefore, the researcher decided to refer to $\chi^{2} / d f$ proposed by Bagozzi and Yi (1988). Table 5 shows that all the values of $\chi^{2} / d f$ were smaller than the three criteria, indicating a good fitness of the models. Moreover, all the indices, except for the values with asterisk, met the criteria proposed by numerous scholars (Henry \& Stone, 1994; Hairs et al., 1998; Hu \& Bentler, 1999; McDonald \& Ho, 2002).

The convergent validity can be ascertained according to the fact that all the SFLs were between 0.67 and 0.86 with their $t$ values being bigger than the 1.96 criteria under $\alpha=.05$ significant level. In addition, all the values of composite validity fell between 0.81 and 0.91 , indicating that the question items under each construct generally produce consistent answers. The values of AVE fell between 0.67 and 0.84 . All these results suggest the models have satisfactory convergent validity. Therefore, the measurement scales are suitable for the data. This is a good sign of the quality of the question items.

Table 5

Measurement Model Fitness

\begin{tabular}{clllll}
\hline Fitness measures & Criteria & CS & CA & PI \\
\hline \multirow{6}{*}{ AFM } & $\chi^{2}$ & smaller & $632.21(p=0.00)$ & $523.21(p=0.00)$ & $619.11(p=0.00)$ \\
& $\chi^{2} / d f$ & $<3$ & 1.231 & 1.412 & 1.623 \\
& GFI & $>0.9$ & 0.92 & 0.93 & 0.92 \\
& AGFI & $>0.9$ & $\mathbf{0 . 8 7 4 ^ { * }}$ & 0.911 & 0.904 \\
& RMR & $<0.08$ & 0.036 & 0.047 & 0.041 \\
& SRMR & $<0.08$ & 0.012 & 0.021 & 0.022 \\
& RMSEA & $<0.08$ & 0.020 & 0.021 & 0.031 \\
\hline \multirow{4}{*}{ IFM } & NFIFI & $>0.9$ & 0.921 & 0.943 & 0.912 \\
& NNFI & $>0.9$ & $\mathbf{0 . 8 9 1 ^ { * }}$ & $\mathbf{0 . 8 7 8 ^ { * }}$ & 0.932 \\
& CFI & $>0.9$ & 0.912 & 0.921 & 0.912 \\
& RFI & $>0.9$ & $\mathbf{0 . 8 7 8 ^ { * }}$ & $\mathbf{0 . 8 9 1}$ & $\mathbf{0 . 8 6 7 ^ { * }}$ \\
\hline \multirow{6}{*}{ PFM } & IFI & $>0.9$ & 0.901 & 0.932 & 0.678 \\
& PNFI & $>0.5$ & 0.612 & 0.721 & 0.701 \\
\hline
\end{tabular}

Note. AFM: absolute fitness measures; IFM: incremental fitness measures; PFM: parisomy fitness measures; CS: customer satisfaction; CA: customers' awareness; PI: purchase intention.

${ }^{*}$ not meeting the criteria.

Finally, in Table 6, discriminant validity is ascertained. This step is considered very important because it helps the researcher to confirm the correlations among the constructs (construct A-H in Table 6). Scholars have argued that there should be low correlations among each construct. In general terms, when low correlations are confirmed, it makes more sense for the researcher to treat each construct as different variables. On the other hand, if high correlations exist, the researcher might consider deleting some construct for the sake of simplicity of the measurement scales. According to Hairs et al. (1998), when the square root of AVE of each construct is bigger than its correlations with other construct, discriminate validity can be confirmed. The results from Table 6 confirmed this criterion. Judging from the results above, the researcher concluded that the measurement 
models in the current study have high validity and reliability.

Table 6

Discriminant Validity of the Measurement Models

\begin{tabular}{|c|c|c|c|c|c|c|c|c|c|}
\hline \multirow{2}{*}{ Constructs } & \multirow{2}{*}{ Number of items } & \multicolumn{8}{|c|}{ Correlation coefficients } \\
\hline & & $\overline{\mathrm{A}}$ & $\mathrm{B}$ & $\mathrm{C}$ & $\mathrm{D}$ & $E$ & $\mathrm{~F}$ & $\mathrm{G}$ & $\mathrm{H}$ \\
\hline A. SA & 4 & $0.89^{1}$ & & & & & & & \\
\hline B. FR & 4 & $0.33^{*}$ & 0.90 & & & & & & \\
\hline C. $\mathrm{S}$ & 4 & $0.32^{*}$ & $0.31^{*}$ & 0.90 & & & & & \\
\hline D. GC & 2 & 0.43 & 0.32 & 0.43 & 0.90 & & & & \\
\hline E. IC & 2 & 0.12 & 0.23 & 0.34 & $0.33^{*}$ & 0.92 & & & \\
\hline F. SC & 2 & 0.21 & 0.45 & 0.28 & $0.42^{*}$ & $0.34^{*}$ & 0.85 & & \\
\hline G. WT & 2 & 0.34 & 0.22 & 0.29 & 0.41 & 0.29 & 0.22 & 0.88 & \\
\hline H. WU & 2 & 0.29 & 0.30 & 0.31 & 0.40 & 0.25 & 0.21 & $0.49^{*}$ & 0.82 \\
\hline
\end{tabular}

Note. ${ }^{1}$ The value in the diagonal line is the square root of AVE of each construct. $* p>.05$.

\section{Results}

Using maximum likelihood solution, AMOS 22 produced the following statistical results: (1) chi-square $\left(\chi^{2}\right)=423.11(p=.00) ;(2)$ normed chi-square $\left(\chi^{2} / d f\right)=1.98 ;(3)$ absolute fit measures (GFI = .92; AGFI = .91; $\mathrm{RMR}=.034$; RMSEA $=.097)$; (4) incremental fit measures $(\mathrm{NNFI}=.91 ; \mathrm{IFI}=.092 ; \mathrm{CFI}=.093)$; and (5) parisomy fit measures $(\mathrm{PGFI}=.61 ; \mathrm{PNFI}=.63 ; \mathrm{CN}=423)$. Except for $\chi^{2}$, all the statistical results showed that the hypothetical model fit the sampled data well. Given the sensitivity of $\chi^{2}$ to sample size, the researcher referred to normed chi-square, which is 1.98 . This meets the requirement of a good fit (e.g., $<3$ ) according to Bagozzi and Yi (1988). In addition, the standardized regression weights for the hypothetical paths, as shown below were all statistically significant.

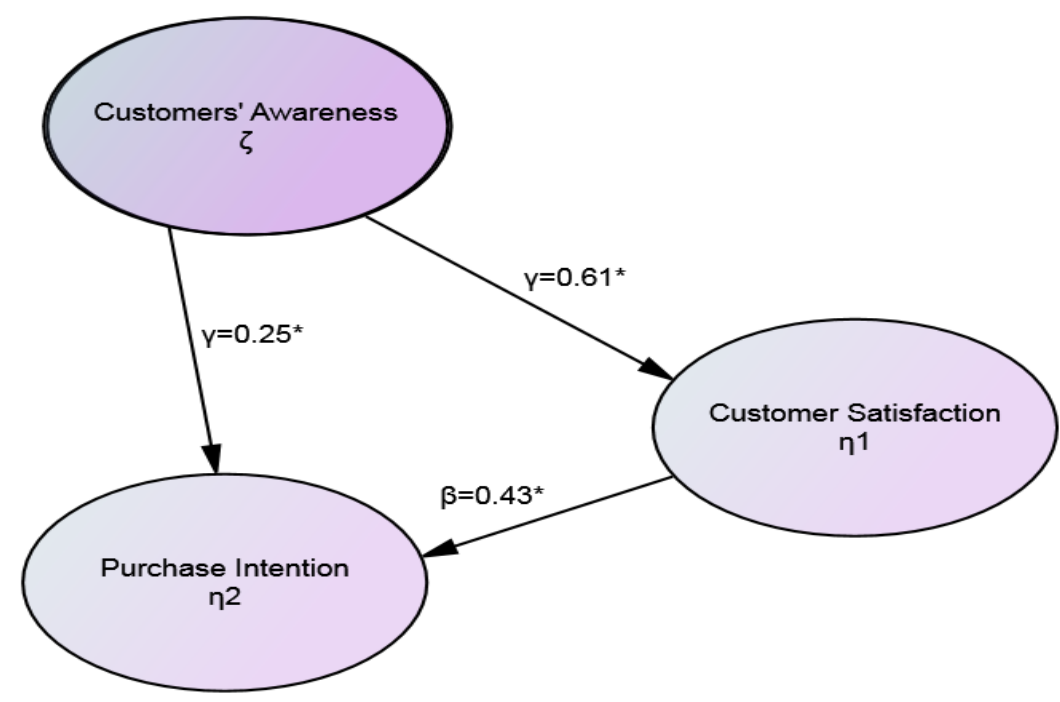

Figure 2. Results of maximum likelihood solution: the hypothetical structural model.

Figure 2 graphically represents the causal relations among the three constructs. Accordingly, the construct of Customers' Awareness (CA) has a direct and positive effect on the construct of Customer Satisfaction (CS), which in turns exerts a positive and direct effect on the construct of Purchase Intention (PI). In addition, CA has 
a positive and direct effect on PI. The total effect of CA on PI is calculated by summing the direct effect of CA on PI and CA's indirect effect on PI (through CS as an intervening factor): $0.25+0.61 * 0.43=0.51$. It should be noted that CA's indirect effect on PI through CS as an intervening factor $(0.262)$ is bigger than CA's direct effect on PI (0.25). This is a good proof that CS assumes a critical mediating role in the established structural equation model. Based on these causal relations, the study retained the first three hypotheses, while rejecting the fourth hypothesis.

\section{Discussion and Conclusion}

The model proposed serves as evidence of the overall statistical exploration on the three constructs which are identified through review of literature. What is noteworthy is that the three constructs measure the response of users rather than translators. In one sense, the theoretical orientation adopted here skews toward the perspective of users. Nevertheless, when referring to the distinction drawn between texts and genres by Hatim and Mason (1997), a subtle or inseparable connection between users and translators surfaces. Brand name translation, when viewed from a micro-perspective, is no more than the so-called texts, which are narrowly defined as a set of words with different rhetorical purposes, e.g., arguing, narrating, etc.. In this regard, brand name translation works at a literal-level, assuming the absence of specific types of users. Apparently, the users of brand name translation are hardly ignorable, which allows for the room to view it more as a genre, in which text producers cater for a particular occasion (Hatim \& Mason, 1997). Following this distinction, it is argued that in this survey, the researcher measured the response of customers and simultaneously gauged the social-cultural practices of translators (Hatim \& Mason, 1997). From a business point of view, the survey also measured the intentionality that the translator imposed on the brand name translation. In brand name translation, translators abide by their awareness of pragmatic considerations, such as the attributes of products being translated, the acceptability of linguistic usage in a certain situation, the feasibility of a translation strategy when considering the time of reception, etc.. A clear set of situational features are formulated by Colina (2003): function of source text, addressees, time of reception, place of reception, medium of transmission, and motive for production. While these concerns are removed, brand name translation might lack intentionality (Hatim \& Mason, 1997).

Viewed from a functional approach of translation process, the statistical exploration serves to highlight three important aspects in the realm of functionalism, widely known as Skopos theory: referential/informative function, expressive function, and operative function. Before the elaboration on Skopos theory goes, Colina's (2003) notion of translation process is fundamental. As Colina (2003) argued, a translation is written for a particular audience and with a specific purpose in mind. If this is true, then the model proposed here serves to identify a clear goal that translators can go for. The model clearly delineated that when customers spot particular use of translation strategy, its effect on increasing their satisfaction of brand translation and the ultimate practical goal of purchase intention is direct and positive. By following this model, translators are provided with a "clearer" purpose in mind. In specific terms, the use of translation strategy might be preferable to the apparent taste of market users. Although this paper does not focus on what type of strategy to be used, the goal-setting process becomes much clearer. In more theoretical terms, when translators are more occupied with the function of the target language, what is being followed is the orientation called the instrumental translation process, in which target language serves to attain the communicative function set by the source language producers in the source language culture (Colina, 2003). Interestingly, the function highlighted here 
receives a broader definitional extension to purchase intention (Chang \& Wildt, 1994; Laroche et al., 1996; Li et al., 2002; Grewal et al., 1998).

A functional approach for analyzing the proposed model is best situated on the conceptualization of the notion of language function. Here, language function is hardly synonymous to textual function, which is defined at a micro level, e.g., how a smaller linguistic constituents can serve the function of convincing, threatening, pleasing (Colina, 2003). Language function, instead, refers to how different levels of structure (for example, phrase, sentence, text) can carry out a certain function. These two nouns are not mutually exclusively, though. What needs to be highlighted is that the function carried out by language can be versatile. In the case proposed here, the translator can simply switch a single Chinese character in his brand name translation to attain the goal of sound translation, while, equally easily, forgoes a certain Chinese character to cater to meaning translation. According to the proposed models, customers' awareness of how a brand name is translated is crucial, exerting both a direct effect on CS and PI. These numerical results, when taken together with the functional approach, become more convincing. Among the three aspects under Skopos theory, translators ideally switch strategies depending on the pragmatic considerations he observes, the goal he sets, and the intentionality he wishes to impose on brand name translation. According to Kang (2014), in different product types, customers value different criteria in terms of translation strategy. For example, in cosmetics and medical care products, semantic ambiguity (referential/informative functions) is valued. In food products, faithful reflection (referential/informative functions) of product contents is valued while smoothness (expressive function) is considered a priority for technology product translation. Based on this result, a speculation is that customers' criteria for a good brand name translation vary according to the pragmatic considerations he identifies with. Built on Kang (2014), the theoretical model and its theoretical relations among CA, CS, and PI can materialize through heeding to the strategy used by translators. Specifically, the initiation of CA can in turn contribute the ultimate goal, e.g., increasing the purchasing intention of customers. Here, the socio-cultural practice of translators is treated as a predicting factor for giving rise to purchase intention, a prime concern for most business owners (Chang \& Wildt, 1994; Laroche et al., 1996; Li et al., 2002; Grewal et al., 1998). A functional approach, at this juncture, does more than a discourse analysis. Rather, it serves as implication and guidelines for brand name translation curriculum design. It also adds more evidence to an objectively formulated framework of brand name translation assessment criteria (Zhang \& Schmitt, 2001; He \& Xiao, 2003).

Proposed in an interdisciplinary manner, generalizing the results of the study to other business contexts should be cautious, considering the complex situational features as specified by Colina (2003), but failed to be considered in this paper. This paper lay out a highly simplified experimental framework, in which translators and customers are not, by definition, taken differently. Some might argue that a translator can also be a customer, and vise versa. This factor has been removed for the sake of experimental feasibility since it was hard to ascertain the exact role, experience and identity in the database mining process. This technical setback, hence, becomes a direction for future academic exploration. Other factors worth manipulating include specifying the demographic background of the customers. A bold speculation is that customers with different gender, social status, budgets might exert different views against the issue of brand name translation. More situational features are not to be excluded either. Finally, the experiment lacks a follow-up interview for more valid and reliable assessment of the self-reported answers based on the scale. All these are highlighted for future academic concern. 


\section{References}

Alashban, A. A., Hayes, L. A., Zinkhan, G. M., \& Balazs, A. L. (2002). International brand-name standardization/adaptation: Antecedents and consequences. Journal of International Marketing, 10(3), 22-48.

Anderson, J. C., \& Gerbing, D. G. (1988). Structural equation modeling in practice: A review and recommended two-step approach. Psychological Bulletin, 103(May), 411-423.

Bagozzi, R. P., \& Yi, Y. (1988). On the evaluation for structural equation models. Journal of Marketing Research, 16, 74-94.

Bollen, K. A. (1989). Structural equations with latent variables. New York: Wiley.

Bollen, K. A., \& Long, J. S. (1993). Testing structural equation models. Newbury Park, CA: Sage.

Boomsma, A. (1982). The robustness of LISREL against small sample sizes in factor analysis models. In K. G. Joreskog \& H. Wold (Eds.), Systems under indirect observation: Causality, structure, prediction (Part I, pp. 149-173). Amsterdam: North-Holland.

Cao, D. (1996). On translational language competence. Babel, 42(4), 231-238.

Chang, T. Z., \& Wildt, A. R. (1994). Price, product information, and purchase intention: An empirical study. Journal of the Academy of Marketing science, 22(1), 16-27.

Colina, S. (2003). Translation teaching: From research to the classroom. New York, San Francisco: McGraw Hill.

Dong, L. C., \& Helms, M. M. (2001). Brand name translation model: A case analysis of US brands in China. The Journal of Brand Management, 2(9), 99-115.

Fan, Y. (2002). The national image of global brands. The Journal of Brand Management, 9(3), 180-192.

Fandos, C., \& Flavián, C. (2006). Intrinsic and extrinsic quality attributes, loyalty and buying intention: An analysis for a PDO product. British Food Journal, 108(8), 646-662.

Francis, N. P., Lam, P. Y., \& Walls, J. (2002). The impact of linguistic differences on international brand name standardization: A comparison of English and Chinese brand names of Fortune-500 companies. Journal of International Marketing, 10(1), 98-116.

Giese, J. L., \& Cote, J. A. (2000). Defining consumer satisfaction. Academy of marketing science review, 1(1), 1-22.

Grewal, D., Krishnan, R., Baker, J., \& Borin, N. (1998). The effect of store name, brand name and price discounts on consumers' evaluations and purchase intentions. Journal of retailing, 74(3), 331-352.

Hair, J. F., Anderson, R. E., Tatham, R. L., \& Black, W. C. (1998). Multivariate data analysis (5th ed.). Upper Saddle River, New Jersey: Prentice-Hall International.

Halim, W. Z., \& Hamed, A. B. (2005). Consumer purchase intention at traditional restaurant and fast food restaurant. In Proceedings of the Australian and New Zealand Marketing Academy (ANZMAC) Conference, Australia (pp. 107-112). Fremantle: School of Business University of Western Australia, Perth.

Hatim, B., \& Mason, I. (1997). The translator as communicator. London \& New York: Routledge.

He, C. S., \& Xiao, Y. N. (2003). Brand name translation in China: An overview of practice and theory. Babel, 49(2), $131-148$.

Henry, J. W., \& Stone, R. W. (1994). A structural equation model of end-user satisfaction with a computer-based medical information system. Information Resources Management Journal (IRMJ), 7(3), 21-33.

Hong, F. C., Pecotich, A., \& Shultz II, C. J. (2002). Brand name translation: Language constraints, product attributes, and consumer perceptions in East and Southeast Asia. Journal of International Marketing, 10(2), 29-45.

Hu, L. T., \& Bentler, P. M. (1999). Cutoff criteria for fit indexes in covariance structure analysis: Conventional criteria versus new alternatives. Structural Equation Modeling: A Multidisciplinary Journal, 6(1), 1-55.

Jöreskog, K. G., \& Sorbom, D. (1989). LISREL 7: A guide to the program and applications (2nd ed.). Chicago: SPSS Inc..

Kang, C. C. (2014, May). Translation of global brand names: A multi-dimensional perspective from translators, customers, and semantics. Paper presented at the 2014 International Symposium on Cross-Cultural Studies, Taipei, Taiwan.

Laroche, M., Kim, C., \& Zhou, L. (1996). Brand familiarity and confidence as determinants of purchase intention: An empirical test in a multiple brand context. Journal of business Research, 37(2), 115-120.

Li, H., Daugherty, T., \& Biocca, F. (2002). Impact of 3-D advertising on product knowledge, brand attitude, and purchase intention: The mediating role of presence. Journal of Advertising, 31(3), 43-57.

Mardia, K. V. (1985). The personality of the retail store. Harvard Business Review, 36, 47-55.

McDonald, R. P., \& Ho, M. H. R. (2002). Principles and practice in reporting structural equation analyses. Psychological methods, $7(1), 64$.

Sandler, D. M., \& Shani, D. (1992). Brand globally but advertise locally?: An empirical investigation. International Marketing Review, 9(4).

Sdobnikov, V. V. (2011). Translation strategy: General definition. Vestnik of Irkutsk State Linguistic University, (1), 165-172. 
Williams, L. J., \& Hazer, J. T. (1986). Antecedents and consequence of satisfaction and commitment in turnover models: A reanalysis using latent variable structural equation models. Journal of Applied Psychology, 71, 219-231.

Zhang, S., \& Schmitt, B. H. (2001). Creating local brands in multilingual international markets. Journal of Marketing Research, $38(3), 313-325$.

\section{Appendix: Survey on Brand Name Translation}

\section{Instruction}

The answers of the survey are for academic research purposes and will be kept confidential.

Date of Survey $(\mathrm{yy} / \mathrm{mm} / \mathrm{dd})$

Signature:

\section{Background Information}

Sex

$\square$ 1. Male

$\square$ 2. Female

Translation-related background

$\square$ 1. With translation-related background

$\square$ 2. Without translation-related background

\section{Customer Satisfaction on Brand Name Translation (CS)}

Please read the following statements and circle 5 (strongly agree), 4 (agree), 3 (neutral), 2 (disagree), and 1 (strongly disagree).

1. The translation is semantically clear.

2. The translation provides sufficient information about what kind of product it is.

3. The literal meaning of the translation is clear.

4. The translation sounds smooth to me.

5. The translation reveals a lot about the attributes of the product.

6. I like the word choice of the translation.

7. This is a proper Chinese translation in terms of wording and collocations.

8. The translation reflects the contents of the product.

9. The translation sounds crisp, clear and impressive.

10. The translation must have been carefully designed and it sounds great.

11. The wording of the translation is easy and understandable.

\begin{tabular}{ll}
12. Customers can easily tell the category of the products simply by reading the translation. 5 \\
\hline
\end{tabular}

\begin{tabular}{|l|l|l|l|l|}
\hline 5 & 4 & 3 & 2 & 1 \\
\hline 5 & 4 & 3 & 2 & 1 \\
\hline 5 & 4 & 3 & 2 & 1 \\
\hline 5 & 4 & 3 & 2 & 1 \\
\hline 5 & 4 & 3 & 2 & 1 \\
\hline 5 & 4 & 3 & 2 & 1 \\
\hline 5 & 4 & 3 & 2 & 1 \\
\hline 5 & 4 & 3 & 2 & 1 \\
\hline 5 & 4 & 3 & 2 & 1 \\
\hline 5 & 4 & 3 & 2 & 1 \\
\hline 5 & 4 & 3 & 2 & 1 \\
\hline 5 & 4 & 3 & 2 & 1 \\
\hline
\end{tabular}

\section{Customer Awareness of Translation Strategy Use (CA)}

1. The Chinese translation conforms to my understanding of Chinese grammatical usage and collocation.

2. Literally, the translation contains certain connotations or implications.

3. To cope with grammatical difference, the translator uses strategies when translating from English source language into Chinese target language.

4. The translator adds certain new meanings which are not found in the originals.

5. The translator uses strategies to add positive image, which is adorable to the Chinese readers.

6. When reading the Chinese translation, the readers can associate it with certain image,

belief or cultural value.

\begin{tabular}{|l|l|l|l|l|l|}
\hline 5 & 4 & 3 & 2 & 1 \\
\hline 5 & 4 & 3 & 2 & 1 \\
\hline from & 5 & 4 & 3 & 2 & 1 \\
\hline 5 & 4 & 3 & 2 & 1 \\
\hline 5 & 4 & 3 & 2 & 1 \\
\hline 5 & 4 & 3 & 2 & 1 \\
\hline
\end{tabular}

\section{Purchase Intention (PI)}

1. After reading the translation, I feel like using the sample of the product.

2. I would like to obtain further information about the product.

3. I am willing to receive further information of the product through e-mails.

4. The translation makes me curious about the product. I wish someone could offer me the sample of the product.

\begin{tabular}{|l|l|l|l|l|}
\hline 5 & 4 & 3 & 2 & 1 \\
\hline 5 & 4 & 3 & 2 & 1 \\
\hline 5 & 4 & 3 & 2 & 1 \\
\hline 5 & 4 & 3 & 2 & 1 \\
\hline
\end{tabular}

